\begin{tabular}{|c|l|}
\hline Title & A nalysis of the effect of heating and re curing on the microstructure of high-strength concrete using X-ray CT \\
\hline Author(s) & Henry, Michael; Darma, Ivan Sandi; Sugiyama, Takafumi \\
\hline Citation & $\begin{array}{l}\text { Construction and Building Materials, 67(Part A), 37-46 } \\
\text { https://doi.org/10.1016/.Conbuildmat.2013.11.007 }\end{array}$ \\
\hline Issue Date & 201409 -30 \\
\hline Doc URL & http://hdl.handle.net/2115/57545 \\
\hline Type & article (author version) \\
\hline File Information & mwhenry - cbm - concrete crack x-ray - manuscript_final-1.pdf \\
\hline
\end{tabular}

Instructions for use 


\title{
ANALYSIS OF THE EFFECT OF HEATING AND RE-CURING ON THE MICROSTRUCTURE OF HIGH-STRENGTH CONCRETE USING X-RAY CT
}

(3)

\begin{abstract}
Microstructure recovery plays an important role in restoring the performance of concrete damaged by fire. This research applied X-ray CT and image analysis techniques to non-destructively examine the internal microstructure of high-strength concrete in order to clarify the effects of heating and re-curing on microstructure characteristics. Heating caused an increase in total pore space due to an increase in connectivity caused by the formation of cracks in the mortar-aggregate interface and bridging cracks. Water re-curing, however, was effective in recovering microstructure through the reduction in connected pore space, with most recovery occurring within seven days.
\end{abstract}

Keywords: Microstructure; connectivity; high temperature; re-curing; X-ray CT; non-destructive evaluation; high-strength concrete 


\section{INTRODUCTION}

Although concrete generally exhibits good fire resistance, exposure to high temperatures can lead to a reduction in overall structural performance including decreased load-carrying capacity, durability and fire resistance. These are caused primarily by chemical changes in the cement paste as well as incompatibility in the thermal behavior of the mortar matrix and coarse aggregates, which lead to weakened matrix strength, coarsened pore structure, and extensive cracking [1]. High-strength concrete in particular has been found to be more susceptible to loss of strength and durability than normal-strength concrete, as well as more likely to suffer from explosive spalling $[2,3]$.

In order to restore safety and performance, repair operations that involve the removal of the damaged concrete and the casting of a patching material are necessary [4]. However, energy and labor costs, as well as waste generation and resource consumption, could be reduced if the performance of the firedamaged concrete could be restored without the need for labor-intensive operations. Past research works have shown that the re-curing of fire-damaged concrete in water or a high humidity environment can lead to the recovery of strength and durability. This recovery has been attributed to the reduction of pore space and regeneration of hydration products from the rehydration of calcium oxide as well as the hydration of unhydrated cement particles [5-7]. Water supply is of particular importance for recovery, as the rate of rehydration is higher in such cases [8]. Furthermore, while high-strength concrete has been found to perform differently under fire loading, it has also been shown to have better recovery under re-curing due to its dense microstructure [8]. Recovery of durability has been attributed to the filling of pore space and healing of cracks as well as the consumption of calcium oxide during rehydration, which reduces the potential for harmful carbonation, but the instability of healed crack areas may limit the strength recovery [9].

Previous studies have made it clear that changes to microstructure properties such as porosity and pore size distribution play an important role in the degradation and recovery of strength and durability. These approaches, however, are generally limited in scale and restricted to either quantitative outputs 
or two-dimensional images. In addition, there is little research which characterizes microstructure changes differentiating between total pore space and isolated and connected pores. Total pore space may have a strong influence on load-carrying properties, whereas permeability may be more dependent upon the characteristics of connected pore space.

X-ray microtomography (X-ray CT) is powerful tool for non-destructively investigating the threedimensional (3D) microstructure of a material. Through X-ray CT and image analysis techniques, the internal pore space of a specimen can be qualitatively and quantitatively analyzed in three dimensions and pores characterized as either isolated or part of a connected pore cluster. Furthermore, imaging may be carried out with specimens composed of cement paste, mortar, or even concrete, thus enabling the examination of composite systems. In addition, as the imaging is non-destructive, the effects of various conditions or tests may be carried out on the same specimen with the same material composition. Considering the strengths of this tool, the objective of this research is to utilize X-ray CT and image analysis techniques to clarify the effect of heating and re-curing on high-strength concrete through characterization of the 3D internal microstructure. Specifically, the effectiveness of water re-curing for recovering the microstructure of fire-damaged high-strength concrete was examined by extraction and quantification of the total, isolated, and connected pore space and compared to the case of air re-curing, which represents a control condition.

\section{EXPERIMENTAL PROGRAM}

An overview of the experimental program is shown in Figure 1. Each step of the program will be introduced in detail in the following sections.

\subsection{Specimen preparation and curing}

Concrete was prepared with a water-cement ratio (W/C) of 0.30 , a very low W/C typical of highstrength cementitious materials. The complete concrete mix proportions are given in Table 1. Ordinary Portland cement (C) was used as the binder, along with fine (S) and coarse $(\mathrm{G})$ aggregates 
1 from the Shizunai River and super plasticizer (SP) and anti-foaming (AF) admixtures for meeting

2 workability requirements. The workability of the fresh concrete was evaluated using the slump flow and air content, which were measured following the (Japanese Industrial Standard) JIS A 1150 and JIS A 1128, respectively. The target slump flow was $45 \mathrm{~cm}$ and the target air content was $5 \%$.

After casting, four cylinders $(100 \times 200 \mathrm{~mm})$ were sealed and cured in the molds for 24 hours, then removed and placed in water curing at $20^{\circ} \mathrm{C}$ for four weeks. A single cylinder was then removed from water curing and a $20 \mathrm{~mm}$ core was extracted from the center of the cylinder. This core was cut into two $20 \mathrm{~mm}$ segments, which were then returned to water curing for another nine weeks. Total curing time from casting to heating was 13 weeks (91 days) in order to achieve a high degree of hydration similar to that of concrete structures in service. The 91-day compressive strength, which was measured using three standard cylinders from the same concrete mix, was $67.5 \mathrm{MPa}$.

\subsection{Heating and re-curing}

Fire exposure was simulated using an electric furnace with a temperature control program. The rate of heat increase was set at $10^{\circ} \mathrm{C}$ per minute until the target exposure temperature of $600^{\circ} \mathrm{C}$ was reached, after which it was maintained for one hour. The target exposure temperature of $600^{\circ} \mathrm{C}$ was selected because the dehydration of calcium hydroxide occurs between $450^{\circ} \mathrm{C}$ and $550^{\circ} \mathrm{C}$ and produces calcium oxide [10], the rehydration of which has been shown to contribute to the recovery of strength and durability performance under re-curing [8]. Therefore, this temperature enabled the examination of the case in which high degrees of both dehydration and rehydration would occur.

After the conclusion of the high temperature exposure, the door of the furnace was opened and the specimens were allowed to cool in the furnace until the internal furnace temperature dropped below $100^{\circ} \mathrm{C}$. Specimens were then removed from the furnace and cooled at room temperature for approximately one hour before being placed in one of two re-curing conditions. Air re-cured specimens were placed in a temperature-controlled environment at $20^{\circ} \mathrm{C}$, whereas water re-cured 
specimens were placed in conditions similar to the initial curing period. Re-curing was carried out for one and four weeks.

\subsection{Image acquisition using $X$-ray microtomography}

As summarized by Promentilla and Sugiyama [11] and Landis and Keane [12], the concept of X-ray microtomography is similar to that of Computed Axial Tomography (CAT or CT) scans in the medical field, in which a 3D digital image is reconstructed from a series of two-dimensional (2D) images or "slices." Each voxel (3D pixel) within the 3D digital image has an associated X-ray absorption value that can be correlated to material density, and thus the internal structure can be determined based on the arrangement of the voxels in a 3D space. The resolution of the image can vary from the sub-micron scale or a few microns (for CT systems using synchrotron radiation with a parallel and monochromatic beam) to tens of microns (for microfocus radiation with a cone beam). There is, however, a trade-off, in that the maximum sample size for the higher-resolution systems is limited to less than a few millimeters, whereas specimens on the scale of a few centimeters may be used with lower resolution systems. In the concrete field, X-ray microtomography has been applied at a variety of scales and to a variety of research areas, including pore structure characterization, freezethaw damage, sulfate attack, damage evolution, and diffusivity in cracks [11,13-18].

In this research, a desktop microfocus CT system was used for acquiring the slice images. The set-up consists of a microfocus X-ray emitter, a rotation table which allows for $360^{\circ}$ imaging, an image intensifier detector with CCD camera, and an image processing unit. Image acquisition was carried out before heating (water re-cured specimen only), after heating, and after one and four weeks of recuring in water and air. As illustrated in Figure 2, the focus area for data acquisition was approximately $11.5 \mathrm{~mm}$ in height, $20.0 \mathrm{~mm}$ in diameter, and roughly centered on the specimen. In this area, 351 slices were obtained. Each slice was 1024 by 1024 pixels in size, with each pixel 22 microns by 22 microns. After image processing and scaling, the voxel size was 22 by 22 by 22 microns.

\section{RESULTS}




\section{3.1. Cross-sectional images of the concrete specimens}

3 Figure 4 shows the cross-sectional images of both concrete specimens after heating. In these images,

4 lighter shades of grey indicate higher density materials, whereas darker shades of grey or black

5 indicate lower density materials or air voids, respectively. In the specimen used to investigate water

6 re-curing, it can be seen that there are several large aggregates occupying various spaces; in particular, some of the aggregates are at the surface of the specimen and were likely cut when the core was extracted from the original concrete cylinder. The shades of these aggregates also vary, which implies that the aggregates in the concrete are of differing mineral compositions. As the thermal behavior of aggregates depends on the mineral composition [7], these images clarify that the concrete specimen, when under heating, will undergo varying degrees of thermal stresses.

For the specimen used to investigate air re-curing, one large aggregate appears to occupy the center of the specimen at lower heights, whereas other smaller aggregates can be seen in the upper part of the specimen and around its surface. In addition, a small void at the surface of the specimen can also be seen in the upper part of the specimen. The aggregates in this specimen are also of varying shades of grey, and thus composed of varying minerals with differing thermal behavior.

As these images were taken after heating, it is possible to visually identify some of the cracks formed in the specimen due to the heating exposure. However, even though the contrast between the pore space (black) and the solids (shades of grey) is high, it is difficult to comprehensively and quantitatively evaluate the effect of heating and re-curing by visual inspection alone. Therefore, it is necessary to apply image analysis techniques to extract and quantify the pore space.

\subsection{Threshold segmentation method for extracting pore space}

Threshold segmentation was applied to separate the pore space from the solids in the specimens. As illustrated in Figure 4, total pore space (which includes both isolated and connected pores) could be extracted by selecting a threshold value from the grey-scale value histogram, which varies by image 
stack, and using that value to convert the grey-scale images to binary black and white images $[16,18]$.

Connected pore space could then be extracted by carrying out cluster multiple labeling (connectivity analysis) to separate the connected and isolated pores. Following the methodology of Hoshen and Kopelman [19] and Ikeda et al. [20], connected pores could be identified using a 6-point connectivity rule in which two voxels can be labeled as "connected" if they share a common face with each other. The entire group of connected voxels is called a cluster, and can be quantified by the number of voxels and their relative position in a 3D space. In this study, the connected pore space was quantified based on the largest connected pore cluster.

\subsection{Characterization of total, connected, and isolated pore spaces}

The results of the threshold segmentation and cluster multiple labeling are summarized in Table 2 for the water re-cured specimen and Table 3 for the air re-cured specimen. From these values, the total pore volume and ratio of isolated and connected pores (Figure 5), as well as the effect of heating and re-curing on the isolated (Figure 6) and connected (Figure 7) pore volumes, could be calculated. In these figures, the volume fraction is reported as a percentage of the total volume.

In the water re-cured specimen, the total pore volume before heating was $6.3 \%$, but this value increased by roughly $3 \%$ due to heating exposure. In addition, the ratio of the volume of the connected pores (the largest connected pore cluster) to the volume of the total pore space - the degree of connectivity - increased by more than three times. However, just seven days of water curing reduced the total pore volume to $5.9 \%$, which was less than the pre-heating value. This was also accompanied by a reduction in the connectivity from 0.60 to 0.36 , which shows that connected pores occupied a greater fraction of the total pore space after seven days of water re-curing than before heating, even though the total pore space was lower than before heating. Further re-curing in water up to 28 days only contributed to a minor reduction in the total pore volume and no change in the connectivity. 
1 The post-heating total pore volume of the air re-cured specimen was slightly higher and the

2 connectivity slightly lower than that of the water re-cured specimen, which may be understood considering the different compositions of the two specimens. Unlike water re-curing, air re-curing did not lead to a large reduction in total pore volume, with a decrease of only $0.6 \%$ even when re-curing was carried out for 28 days. The connectivity, on the other hand, decreased slightly from 0.57 to 0.47 over the same 28-day period, but this was much lower than the decrease observed in the case of water re-curing. Similar to water re-curing, the largest changes in total pore volume and connectivity occurred within the first seven days of air re-curing.

Heating lead to a large increase of $4.6 \%$ in the volume of connected pores but a slight decrease of $1.5 \%$ in the volume of isolated pores. As the total volume also increased due to heating, these trends indicate that the decrease in isolated pores was caused by the increase in connectivity, which joined isolated pores to the connected pore cluster, and the further increase in total pore space occurred within the connected cluster. Both water and air re-curing up to 28 days led to decreases in the volume of connected pores, although the effect was more pronounced for water $(-3.6 \%)$ than for air $(-1.2 \%)$, and most reduction occurred within the first seven days of re-curing. In the case of the isolated pore space, however, water did not appear to have an affect on the isolated pore volume, and only a slight increase of $0.6 \%$ was observed by 28 days under air re-curing.

\subsection{Segmented images of the connected pore space}

Following the cluster multiple labeling, slices images of the connected pore space were extracted for both concrete specimens. The resultant images are shown in Figure 8 for water re-curing and Figure 9 for air re-curing.

In the water re-cured specimen, some connected pore space can be observed even before heating exposure. By cross-examining these segmented images with the original images, this connected pore space can be understood to be initial defects which existed within aggregates in the concrete, and it was confirmed that no cracks initially existed within the concrete matrix. However, the post-heating 
images clearly show that cracks formed in several ways: around aggregates which were completely inside the specimen; cracks which bridged between different aggregates; and cracks which bridged between aggregates and large air voids. However, the initial defects within the aggregates did not appear to grow as a result of the heating exposure, although they were identified as connected to the largest pore cluster via the cluster multiple labeling analysis. After seven days of water re-curing, the connected pore space decreased significantly, and little change in the segmented images was observed between seven and 28 days of water re-curing. A comparison of the pre-heating and 28 -day water recured images shows the most notable change is the presence of a cluster of connected pores concentrated in the center of the specimen, as the initial defects which existed before heating appear unchanged after re-curing.

In the air re-cured specimen, cracks formed in a similar manner as in the water-re-cured specimen: distinct crack surfaces can seen in aggregate-mortar interface, along with some crack bridging. In addition, some connected pore space may also be found inside aggregates, which are possibly initial defects from before heating. The connected pore space appears to be affected by air re-curing, as some pores disappear whereas others appear after seven days of air re-curing. In particular, some large pores which were part of the connected pore cluster after heating were no longer connected after 7 days; conversely, the air void at the surface in the upper part of the specimen was not initially connected to the largest pore cluster after heating but was labeled as part of the connected pore cluster at 7 days. Little change in the segmented images can be observed between 7 and 28 days of air recuring.

\subsection{Pore size distribution of connected pore space}

Figures 10 and 11 show the 3D visualizations and pore size distributions of the connected pore space in the water and air re-cured specimens, respectively, for the after heating and 28-day re-curing conditions. The 3D visualizations were reconstructed from the stack of segmented slice images, and the pore size distribution was calculated by applying the local thickness method to the 3D connected pore volume $[21,22]$. The mean pore diameter was then calculated from the pore size distribution. 
2 After heating, the connected pore space in the water re-cured specimen can be seen to extend in all

3 three directions in the specimen. Some large air voids can also be seen, along with semi-smooth surfaces which indicate mortar-aggregate interfaces. The mean pore size was 208.4 micrometers after heating, with roughly $60 \%$ of the connected pore volume occupied by pores less than 150 micrometers in size. After 28 days of water re-curing, the mean pore size was reduced by slightly more than 13 micrometers; correspondingly, pores less than 150 micrometers in size occupied roughly $71 \%$ of the connected pore volume, which was an increase of $11 \%$ relative to the post-heating condition. The 3D visualization also shows a marked decrease in the connected pore space.

The 3D visualization of the air re-cured specimen after heating is similar in appearance to that of the water re-cured specimen, with distinct semi-smooth surfaces in the mortar-aggregate interfaces and some large air voids. The post-heating mean pore diameter was 241.8 micrometers, and $49.5 \%$ of the connected pore volume was occupied by pores 150 micrometers or smaller in size. While air re-curing did lead to a slight reduction in the connected pore volume, it can be seen that the mean pore diameter increased by more than 160 micrometers after 28 days and the volume occupied by pores less than 150 micrometers in size decreased to $47.5 \%$. These changes may be attributed to the inclusion of the large surface air void in the connected pore space from 7 days of re-curing onwards, which resulted in a higher relative frequency for larger pore diameters at 28 days compared to the relative frequency after heating.

\section{DISCUSSION}

\subsection{Effect of heating on microstructure}

As the concrete specimens contained mortar and aggregate phases, the formation of cracks and the increase in pore space may be driven by a combination of chemical changes in both the cement paste and aggregates. Around $550^{\circ} \mathrm{C}$, cement paste has been found to decompose due to the dehydration of calcium hydroxide and C-S-H gel, which leads to shrinkage starting at temperatures as low as $300^{\circ} \mathrm{C}$ 
1 [10]. Coupled with the expansion of aggregates, which depends on the mineral composition, this

2 difference in thermal behaviors can lead to extensive cracking [7]. Under the $600^{\circ} \mathrm{C}$ heating in this

3 study, cracks were observed to form primarily in the interface between the mortar and aggregates, as

4 well as radially outwards from the aggregates. The former cracking behavior is clearly driven by the

5 difference in the thermal behaviors of the cement paste and aggregates under heating, as the cracks

6 formed three-dimension ovoids in the pore space which surrounded aggregates. The latter cracking

7 behavior is likely driven by the expansion of the aggregates, as these cracks were seen to bridge

8 between aggregates or intersect weak spaces in the mortar matrix such as large isolated pores. Due to

9 the development of these bridging cracks, the volume of isolated pores decreased under heating as they became joined to the connected pore space, and thus the connected pore volume increased greatly. Furthermore, as these bridging cracks intersected aggregates the increase in connected pore space also included the crack surfaces in the mortar-aggregate interface, which contributed to the increase in total pore space.

The change in total pore space fraction observed in this study also supports the results of previous investigations on high-strength concrete under fire loading, which showed that the strength loss is not as severe as the loss of durability [8]. It was found that there was a much greater increase in the connectivity (and thus, the fraction of total pore space occupied by connected pores) than there was in the total pore space. As durability is dependent on connected pore space, these results suggest that the loss of durability due to heating may be greater than the loss of strength.

\subsection{Effect of re-curing on microstructure}

As indicated in previous studies, water re-curing was shown to be much more effective for reducing pore volume and pore size than air re-curing, and this effectiveness could be viewed at multiple levels. Total pore volume after 28 days of water re-curing decreased by one-third relative to the post-heating pore volume. This reduction occurred mainly through a reduction in the volume of connected pores. 
1 the total pore space compared to $60 \%$ after heating, and the mean pore size was also reduced, which resulted in a finer pore structure.

A previous study reported that extended water re-curing led to an increase in porosity and pore size due to expansion generated by the rehydration of calcium oxide into calcium hydroxide [8], but this phenomenon was not observed in this study. However, one mechanism for crack self-healing in concrete is expansion of hydration products or other agents [23], and thus the observed reduction in crack width under water re-curing may have been partly driven by the expansion of rehydrated calcium oxide. An increase in pore size may have been prevented by the large size of the aggregates relative to the total specimen size, which could have acted as a restraining force during the re-curing period.

The majority of the microstructure recovery under water supply occurred within the first seven days of re-curing. While some studies have also reported high degrees of rehydration within the first seven days of re-curing [8], in general the recovery of concrete properties has been observed to occur over a period of weeks or months $[6,8,24]$. The fast pace of microstructure recovery was assisted by the high connectivity after heating and the relatively small specimen size, which enabled the quick supply of water to the dehydrated cement particles. It is not clear, however, whether the recovery of the connected pore space was achieved by crystalline regrowth, expansion under rehydration, or some other self-healing mechanism. The hydration of unhydrated cement particles, which may remain in the matrix even after 91 days of water re-curing due to the low water-cement ratio of the mix, may also have contributed to the microstructure recovery, but the relative contribution of these different mechanisms is also unclear. Furthermore, it could be seen that, even at 28 days, some connected pore space remained at the center of the specimen and in the aggregate-mortar interfaces, suggesting that they did not receive water supply for re-curing. A previous study on diffusivity in cracked concrete using X-ray CT found that, even when pores are connected, water may not fill the entire cracked space under natural immersion conditions and, furthermore, diffusivity in the crack is partially dependent on the crack width opening [18]. While it is not possible to determine whether water supply 
occurred in the central area of the specimen or not, the lack of recovery in that area, along with the results of the previous study, suggest that the change in crack opening size at the surface of the specimen due to re-curing may have played a part in reducing or preventing water supply to these connected pores, despite the fact that the belonged to the largest connected pore cluster.

A comparison of the microstructure before heating and after 28 days of re-curing shows that, while the total pore volume after water re-curing became less than that before heating, the connectivity of the total pore structure after 28 days was much higher. The volume of isolated pores decreased under heating due to crack bridging but was unaffected by water re-curing, which may be attributed to the lack of water supply paths from the exposure surface. As a result, there were fewer isolated pores after re-curing than before heating, leading to a re-cured total pore space which, although similar in total volume, was much more connected than before heating. A portion of this connected pore space was occupied by the identified initial defects inside aggregates, which remained unaffected by both heating and re-curing.

Under air re-curing conditions, only a small decrease in the total pore volume was observed over the 28-day period, along with a slight decrease in connectivity and slight increase in isolated pores. Inspection of the segmented slice images, however, suggests that some pores which were not connected after heating became connected after seven days of air re-curing. In particular, there was a large increase in the mean pore size due to the inclusion of a surface air void which joined the connected pore space and shifted the pore size distribution considerably. The reason why this void was not connected after heating but became connected after 7 days is unclear; however, dimensional changes in the concrete specimen due to the cooling of the mortar and aggregate phases may have contributed to some changes in the connectivity of the pore space. In contrast to water curing, however, it is clear that, overall, air re-curing did not lead to a significant improvement in the microstructure.

\subsection{Implications for the recovery of concrete properties}


1 While this study did not directly evaluate mechanical properties, such as strength or permeability, of

2 the concrete specimens, the changes in the microstructure due to heating and re-curing suggest several points for understanding their recovery. When compared to the post-heating condition, the total pore space after 28 days of water re-curing decreased both in volume and connectivity, and the pore size distribution was finer. As porosity and pore size are both governing factors related to strength and permeability, the observed changes in microstructure imply that significant strength and permeability recovery occurred in the specimen. However, the connectivity of the specimen, while reduced compared to the post-heating condition, did not fully recovery to the pre-heating level, which suggests that the durability also may not have recovered fully. However, it is necessary to consider the structure of the connected pore space. Water supply occurred radially from the outside of the specimen, with no water penetration occurring from the top or bottom. The cross-sectional images show that the residual connected pore cluster consists mainly of defects within the aggregates and pores generally concentrated in the center of the specimen. Water re-curing first served to heal surface cracks, which thus reduced the permeability even though connected pores remained in the center of the specimen. Therefore, even though the connectivity did not recover to pre-heated levels, it is reasonable to assume that the permeability of the specimen was recovered more than the relative connectivity suggests.

The reduction in connectivity from after heating to 28 days also has some implications for the strength recovery. While the connected pore volume decreased under water re-curing, the mechanical strength of the recovered connected areas (crack surfaces) is not established. Previous research suggested that, while crack self-healing in fire-damaged mortar may serve to improve durability, the mechanical strength of the self-healed areas may be less than that of the surrounding matrix, and thus the strength of the specimen will not fully recover even if crack self-healing occurs [9]. Although the total pore space after 28 days of water re-curing was similar to that before heating, this reduction was achieved mainly through a reduction in the connected pore space, the mechanical strength of which is unclear. It will be necessary in the future to clarify the effect of the healed areas, as well as the relative contribution of isolated and connected pores towards the load-carrying capacity. 
2 In addition, although the microstructure of the air re-cured specimen may not have undergone significant changes during re-curing, this does not imply that air re-curing carries no benefit for the recovery of concrete properties. Specifically, fire-damaged concrete left in atmospheric conditions has been found to undergo extensive carbonation due to the reaction of atmospheric $\mathrm{CO}_{2}$ with calcium oxide produced by the dehydration of hydration products [10]. In reinforced concrete this leads to deterioration over time, but in non-reinforced concrete carbonation serves as a major contributor to strength recovery by producing a denser pore structure. However, the effects of carbonation on the microstructure were not observed in this study.

\section{CONCLUSION}

This investigation examined the effects of heating and re-curing on the microstructure of highstrength concrete by examining the changes in total, connected and isolated pore space using X-ray $\mathrm{CT}$ and image analysis techniques. The major results are summarized as follows:

1) Heating of the high-strength concrete specimens resulted in the formation of cracks in the mortaraggregate interface and bridging cracks between different aggregates or between aggregates and voids. As a result, while total pore volume increased by roughly 1.5 times, this was mainly driven by an increase of 3.5 times in the connectivity of the void space, as cracks caused by heating joined isolated pores to the connected void space, and thus reduced the isolated pore space relative to the pre-heating condition.

2) Water re-curing after heating was shown to be effective for microstructure recovery, as the total pore volume after 28 days of re-curing was just two-thirds the post-heating volume. This reduction mainly occurred through a reduction in the connectivity, which decreased from 0.60 to 0.36 over 28 days. The mean pore size of the connected pore space also decreased slightly over the 28-day recuring period, and the pore size distribution became finer. However, compared to the pre-heating 
1 condition, the total pore space after 28 days of water re-curing had a higher connectivity even though

2 the total pore volume was similar, although these connected pores were mainly concentrated in the

3 center of the specimen. The majority of the microstructure recovery occurred within the first seven

4 days of re-curing.

5

6 3) Air re-curing did not lead to significant recovery of the microstructure. Only a small decrease in the

7 total pore volume was observed over the 28-day re-curing period, along with a slight decrease in

8 connectivity and a slight increase in the volume of isolated pores. There was, however, a large

9 increase in the mean pore size due to the inclusion of a surface air void in the connected pore space

10 after seven days of air re-curing.

11

12 While this investigation demonstrated the effectiveness of water re-curing for reducing total pore space and the healing of cracks (connected pore space), the chemical reactions driving the changes in the microstructure were not concurrently investigated, nor was the recovery of microstructure directly connected to the recovery of properties such as strength or permeability. In addition, the resolution of the X-ray CT images was limited to a scale of 22 micrometers, which fails to capture conditions in the nano-scale pore structure and micro-cracking. It will be necessary for future studies to integrate X-ray CT examination of the microstructure with chemical analyses and mechanical tests, as well as other microstructure tests such as mercury intrusion porosimetry, in order to comprehensively clarify the mechanism of the re-curing phenomenon across various scales. 
2

3 This research was partially supported by the Japan Society for the Promotion of Science (Scientific 4 Research B, no. 23360187). 


\section{REFERENCES}

2

3 [1] Bazant ZP, Kaplan MF. Concrete at high temperatures. London: Longman Group. 1996.

4

5 [2] Poon CS, Azhar S, Anson M, Wong YL. Comparison of the strength and durability performance

6 of normal and high strength pozzolanic concretes at elevated temperatures. Cement and Concrete

$7 \quad$ Research 2001; 31(9): 1291-1300.

8

9 [3] Phan LT. High-strength concrete at high temperature: an overview. In: Konig G, Dehn F, Faust T, editors. Proceedings of the Sixth International Symposium on the Utilization of High Strength/High Performance Concrete Vol. 1, 2002, p. 501-518.

12

[4] Tovey AK. Assessment and repair of fire-damaged concrete structures - an update. In: Evaluation and repair of fire damage to concrete SP-92, Farmington Hills: American Concrete Institute; 1986, p. $47-62$.

[5] Crook DN, Murray MJ. Regain of strength and firing of concrete. Magazine of Concrete Research 1970; 22(72): 149-154.

[6] Sarshar R, Khoury GA. Material and environmental factors influencing the compressive strength of unsealed cement paste and concrete at high temperatures. Magazine of Concrete Research 1993; 45(162): 51-61.

[7] Lin WM, Lin TD, Powers-Couche LJ. Microstructures of fire-damaged concrete. ACI Materials Journal 1996; 93(3): 199-205.

[8] Poon CS, Azhar S, Anson M, Wong YK. Strength and durability recovery of fire-damaged concrete after post-fire curing. Cement and Concrete Research 2001; 31(9): 1307-1318. 
2 [9] Henry M, Suzuki M, Kato Y. Behavior of fire-damaged mortar under variable re-curing conditions.

3 ACI Materials Journal 2011; 108(3): 281-289.

4

[10] Taylor, HFW. Cement Chemistry. London: Thomas Telford Publishing. 1997.

6

7 [11] Promentilla MAB, Sugiyama T. X-ray microtomography of mortars exposed to freezing-thawing 8 action. Journal of Advanced Concrete Technology 2010; 8(2): 97-111.

9

[12] Landis EN, Keane DT. X-ray microtomography. Materials Characterization 2010; 61: 1305-1316.

[13] Naik NN, Jupe AC, Stock SR, Wilkinson AP, Lee PL, Kurtis KE. Sulfate attack monitored by microCT and EDXRD: influence of cement type, water-to-cement ratio, and aggregate. Cement and Concrete Research 2006; 36: 144-159.

[14] Elaqra H, Godin N, Peix G, Mili MR, Fantozzi G. Damage evolution analysis in mortar during compressive loading using acoustic emission and X-ray tomography: effects of the sand/cement ratio. Cement and Concrete Research 2007; 37(5): 703-713.

19

[15] Sugiyama T, Promentilla MAB, Hitomi T, Takeda N. Application of synchrotron microtomography for pore structure characterization of deteriorated cementitious materials due to leaching. Cement and Concrete Research 2010; 40(8): 1265-1270.

[16] Promentilla MAB, Sugiyama T, Hitomi T, Takeda N. Characterizing the 3D pore structure of hardened cement paste with synchtron microtomography. Journal of Advanced Concrete Technology 2008; 6(2): 273-286. 
1 [17] Promentilla MAB, Sugiyama T, Hitomi T, Takeda N. Quantification of toruosity in hardened

2 cement paste using synchrotron-based X-ray computer microtomography. Cement and Concrete

3 Research 2009; 39(6): 548-557.

4

5 [18] Darma IS, Sugiyama T, Promentilla MAB. Application of X-ray CT to study diffusivity in 6 cracked concrete through the observation of tracer transport. Journal of Advanced Concrete 7 Technology 2013; 11: 266-281.

8

9 [19] Hoshen J, Kopelman, R. Percolation and cluster distribution I. Cluster multiple labeling technique and critical concentration algorithm. Physical Review B 1976; 14: 3438-3445.

[20] Ikeda S, Nakano N, Nakashima Y. Three-dimensional study on the interconnection and shape of crystals in a graphic granite by X-ray CT and image analysis. Mineralogical Magazine 2000; 64(5): 945-959.

[21] Hildebrand T, Rúegsegger P. A new method for the model-independent assessment of thickness in three-dimensional images. Journal of Microscopy 1997; 185: 67-75.

[22] Dougherty R, Kunzelmann K. Computing local thickness of 3D structures with ImageJ. Microscopy and Microanalysis 2007; 12(Suppl.2): 1678-1679.

[23] Ahn TH, Kishi T. Crack self-healing behavior of cementitious composites incorporating various mineral admixtures. Journal of Advanced Concrete Technology 2010; 8(2): 171-186.

[24] Harada T, Takeda J, Yamane S, Furumura F. Strength, elasticity and thermal properties of concrete subjected to elevated temperatures. In: ACI Special Publication SP-34 Concrete for Nuclear Reactors, Detroit: American Concrete Institute; 1972, p. 377-406. 
$3 \quad$ List of Tables

4 Table 1: Concrete mix proportion and properties

5 Table 2: Summary of pore space characteristics for water re-curing specimen

6 Table 3: Summary of pore space characteristics for air re-curing specimen

7

\section{$8 \quad$ List of Figures}

9 Figure 1: Overview of the experimental program

10 Figure 2: Details of X-ray CT specimen and 3D digital image reconstruction

11 Figure 3: Cross-sectional images of concrete specimens (after heating)

$12 \quad$ Figure 4: Method for extracting total pore space and identifying isolated and connected pores

13 Figure 5: Total pore volume and fraction of isolated and connected voids

14 Figure 6: Effect of re-curing condition on the change in connected pore volume

15 Figure 7: Effect of re-curing condition on the change in isolated pore volume

16 Figure 8: Images of connected pore space in water re-cured specimen

17 Figure 9: Images of connected pore space in air re-cured specimen

18 Figure 10: 3D visualizations and pore size distributions of connected pore space in water re-cured

19 specimen

20 Figure 11: 3D visualizations and pore size distributions of connected pore space in air re-cured

21 specimen 
Table 1: Concrete mix proportions and properties

\begin{tabular}{|c|c|c|c|c|c|c|c|c|c|c|c|}
\hline \multirow[b]{2}{*}{$\mathrm{W} / \mathrm{C}$} & \multirow[b]{2}{*}{$\mathrm{s} / \mathrm{a}$} & \multirow{2}{*}{$\begin{array}{c}\text { Max. } \\
\text { agg. } \\
\text { size } \\
(\mathrm{mm}) \\
\end{array}$} & \multicolumn{4}{|c|}{$\left(\mathrm{kg} / \mathrm{m}^{3}\right)$} & \multicolumn{2}{|c|}{$(\mathrm{C} \times \%)$} & \multirow{2}{*}{$\begin{array}{l}\text { Slump } \\
\text { flow } \\
(\mathrm{cm})\end{array}$} & \multirow[b]{2}{*}{$\begin{array}{l}\text { Air } \\
(\%)\end{array}$} & \multirow{2}{*}{$\begin{array}{l}\text { 91-day } \\
\text { comp. } \\
\text { strength } \\
(\mathrm{MPa})\end{array}$} \\
\hline & & & W & $\mathrm{C}$ & S & $\mathrm{G}$ & SP & $\mathrm{AF}$ & & & \\
\hline 0.30 & 0.48 & 25 & 159 & 530 & 796 & 903 & 0.9 & $\begin{array}{c}0.00 \\
6\end{array}$ & 46.7 & 5.1 & 67.5 \\
\hline
\end{tabular}

Table 2: Summary of pore space characteristics for water re-curing specimen

\begin{tabular}{|c|c|c|c|c|}
\hline & $\begin{array}{l}\text { Before } \\
\text { heating }\end{array}$ & $\begin{array}{c}\text { After } \\
\text { heating }\end{array}$ & $\begin{array}{c}7 \text { days } \\
\text { re-curing }\end{array}$ & $\begin{array}{c}28 \text { days } \\
\text { re-curing }\end{array}$ \\
\hline Total volume $\left(\mathrm{mm}^{3}\right)$ & 3367.9 & 3367.9 & 3367.9 & 3367.9 \\
\hline \multicolumn{5}{|l|}{ Total pore space } \\
\hline No. voxels & $19,988,915$ & $29,697,396$ & $18,681,700$ & $17,630,066$ \\
\hline Volume $\left(\mathrm{mm}^{3}\right)$ & 212.8 & 316.2 & 198.9 & 187.7 \\
\hline Connectivity & 0.17 & 0.60 & 0.36 & 0.36 \\
\hline \multicolumn{5}{|c|}{ Connected pore space (largest cluster) } \\
\hline No. voxels & $3,398,116$ & $17,767,294$ & $6,758,065$ & $6,287,854$ \\
\hline Volume $\left(\mathrm{mm}^{3}\right)$ & 36.2 & 189.2 & 72.0 & 67.0 \\
\hline \multicolumn{5}{|l|}{ Isolated pore space } \\
\hline No. voxels & $16,590,799$ & $11,930,102$ & $11,923,635$ & $11,342,212$ \\
\hline Volume $\left(\mathrm{mm}^{3}\right)$ & 176.7 & 127.0 & 127.0 & 120.8 \\
\hline
\end{tabular}

5

Table 3: Summary of pore space characteristics for air re-curing specimen

\begin{tabular}{|c|c|c|c|c|}
\hline & $\begin{array}{l}\text { Before } \\
\text { heating }\end{array}$ & $\begin{array}{c}\text { After } \\
\text { heating }\end{array}$ & $\begin{array}{l}7 \text { days } \\
\text { re-curing }\end{array}$ & $\begin{array}{l}28 \text { days } \\
\text { re-curing }\end{array}$ \\
\hline Total volume $\left(\mathrm{mm}^{3}\right)^{*}$ & - & 3483.2 & 3287.0 & 3244.7 \\
\hline \multicolumn{5}{|l|}{ Total pore space } \\
\hline No. voxels & - & $32,325,343$ & $28,915,522$ & $28,380,419$ \\
\hline Volume $\left(\mathrm{mm}^{3}\right)$ & - & 344.2 & 307.9 & 302.2 \\
\hline Connectivity & - & 0.57 & 0.48 & 0.47 \\
\hline \multicolumn{5}{|c|}{ Connected pore space (largest cluster) } \\
\hline No. voxels & - & $18,386,042$ & $13,839,145$ & $13,447,567$ \\
\hline Volume $\left(\mathrm{mm}^{3}\right)$ & - & 195.8 & 147.4 & 143.2 \\
\hline \multicolumn{5}{|l|}{ Isolated pore space } \\
\hline No. voxels & - & $13,939,301$ & $15,076,377$ & $14,932,852$ \\
\hline Volume $\left(\mathrm{mm}^{3}\right)$ & - & 148.4 & 160.5 & 159.0 \\
\hline
\end{tabular}

*Note: total volume varies due to image trimming during analysis

\section{8}


1
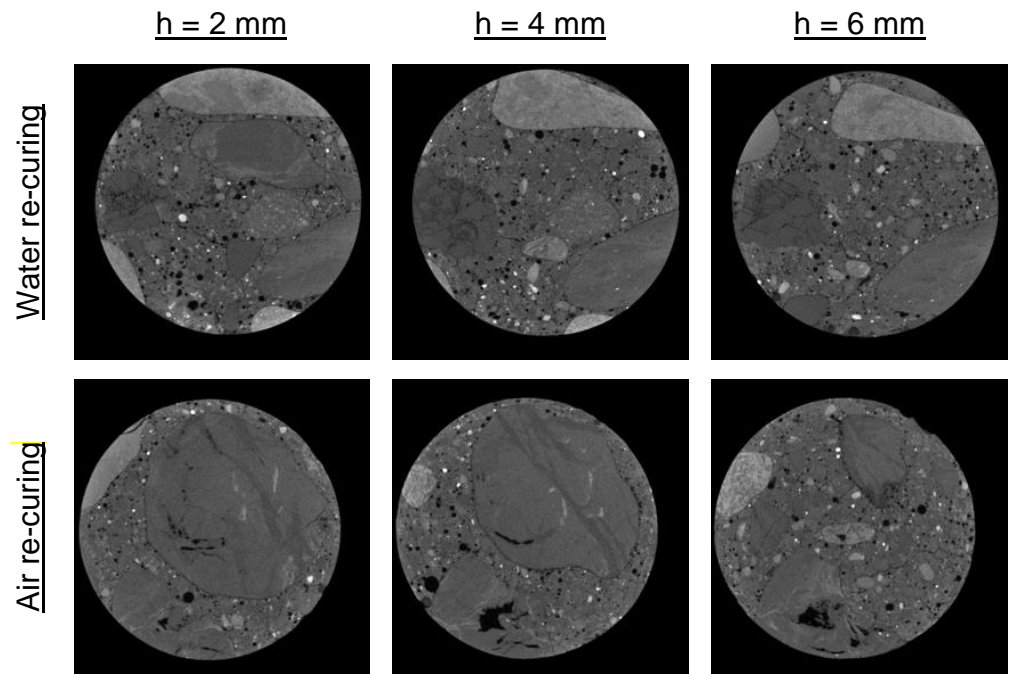

Series of slices

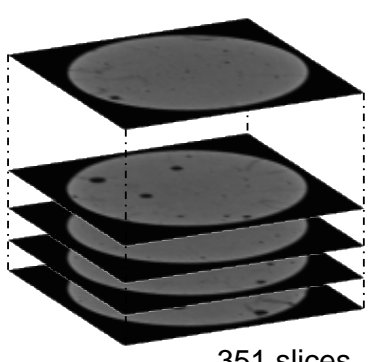

351 slices
Figure 1: Overview of the experimental program

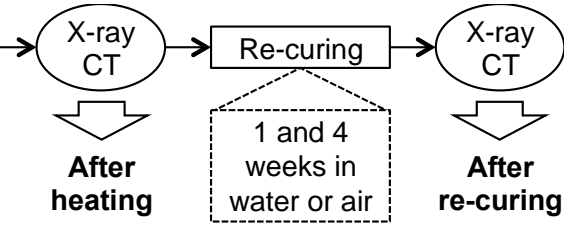

re-curing

Figure 2: Details of X-ray CT specimen and 3D digital image reconstruction

\section{D volume}

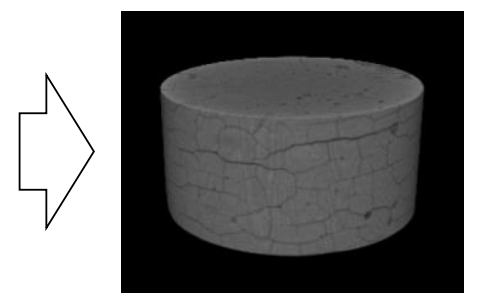




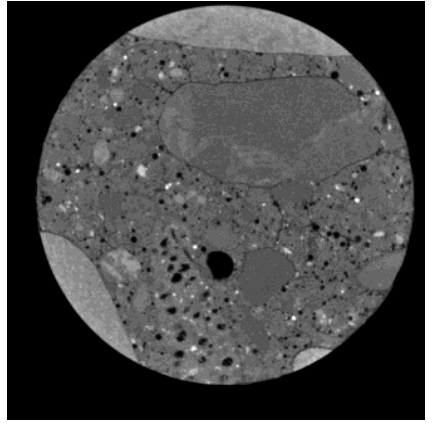

1) Original grey-scale image

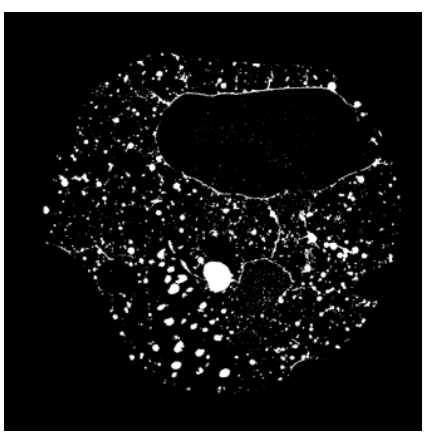

3) Segmented image where white indicates total pore space

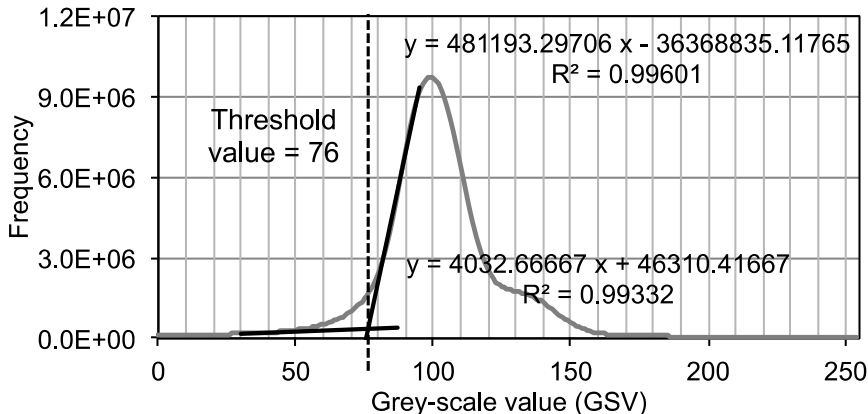

2) Establishment of threshold based on GSV distribution

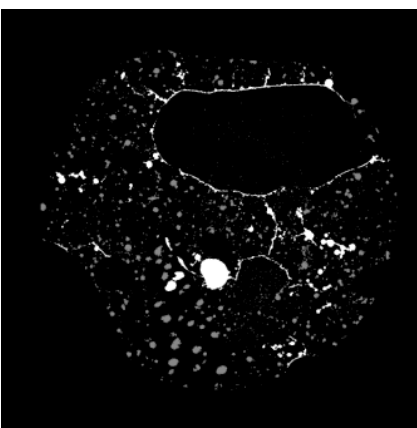

4) Isolated pores are converted to grey through connectivity analysis

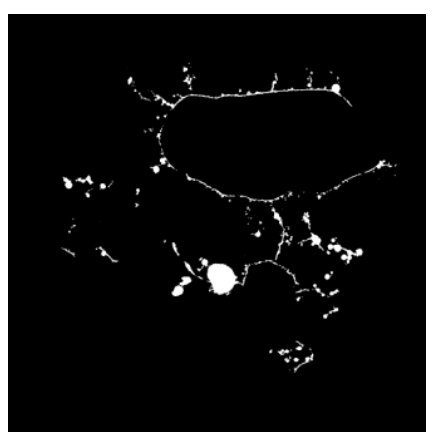

5) Connected pore space (crack) is extracted

Figure 4: Method for extracting total pore space and identifying isolated and connected pores

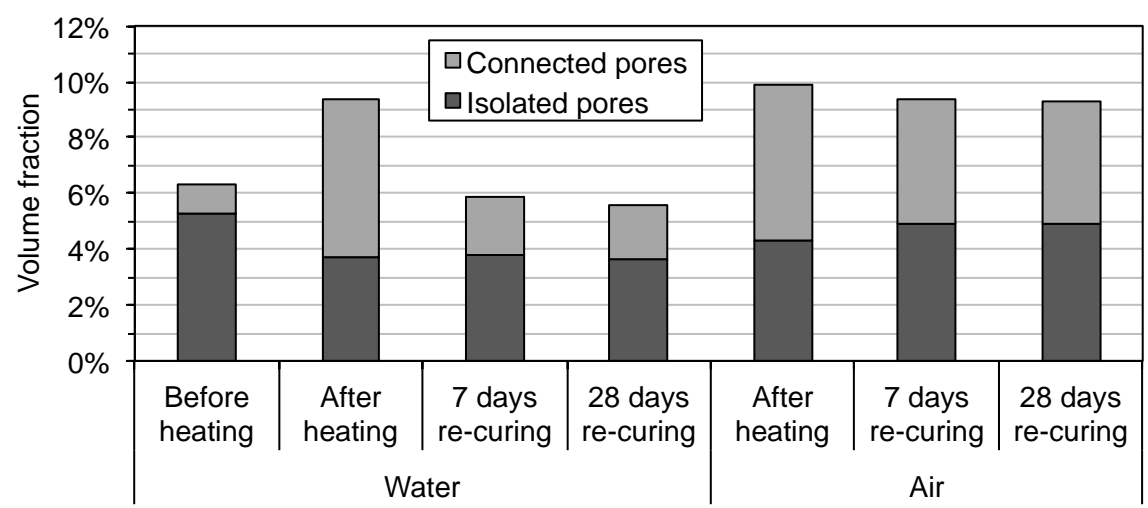

Figure 5: Total pore volume and ratio of isolated and connected pores 


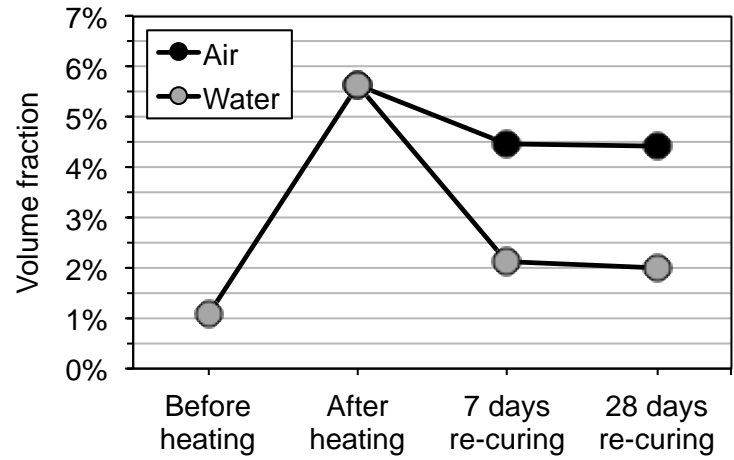

Figure 6: Effect of re-curing condition on the change in connected pore volume 3

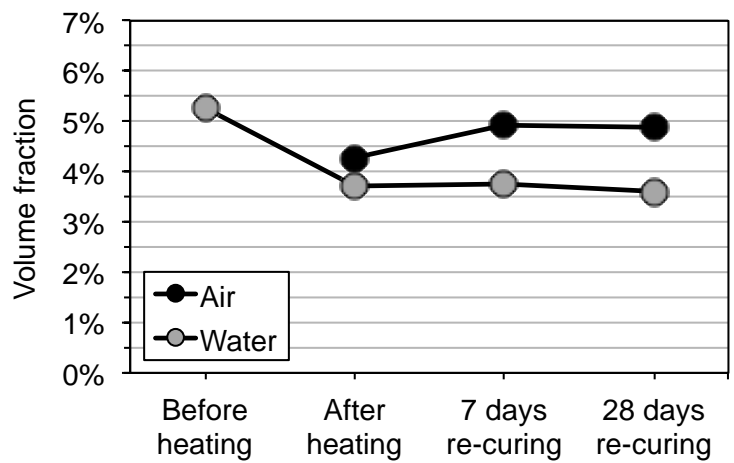

Figure 7: Effect of re-curing condition on the change in isolated pore volume 6 

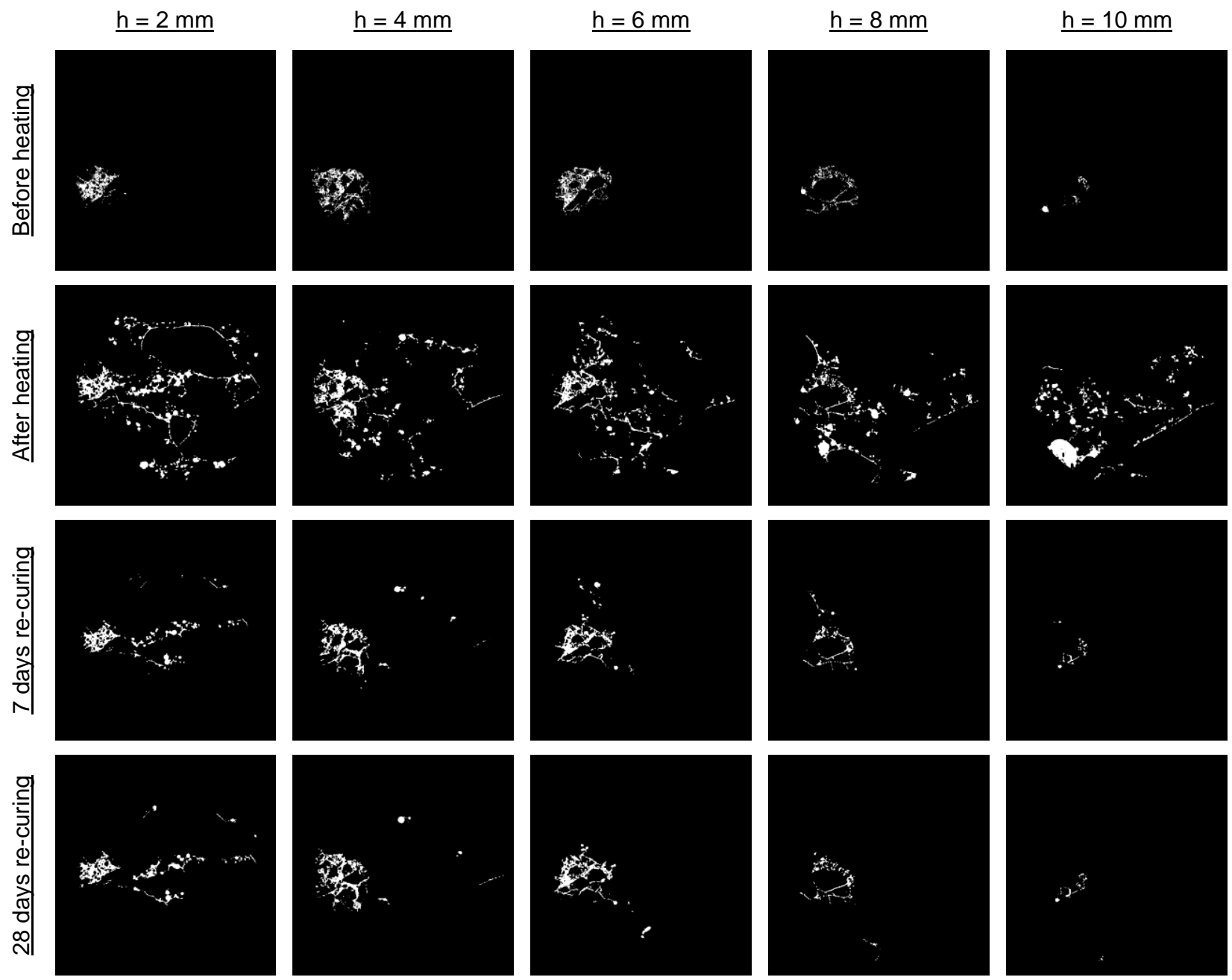

Figure 8: Images of connected pore space in water re-cured specimen 


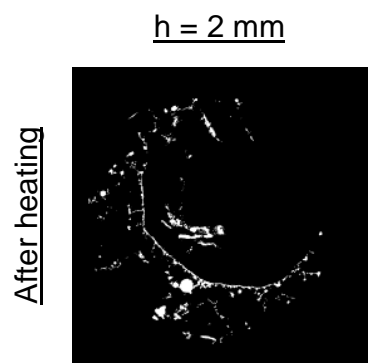

$\underline{h}=4 \mathrm{~mm}$
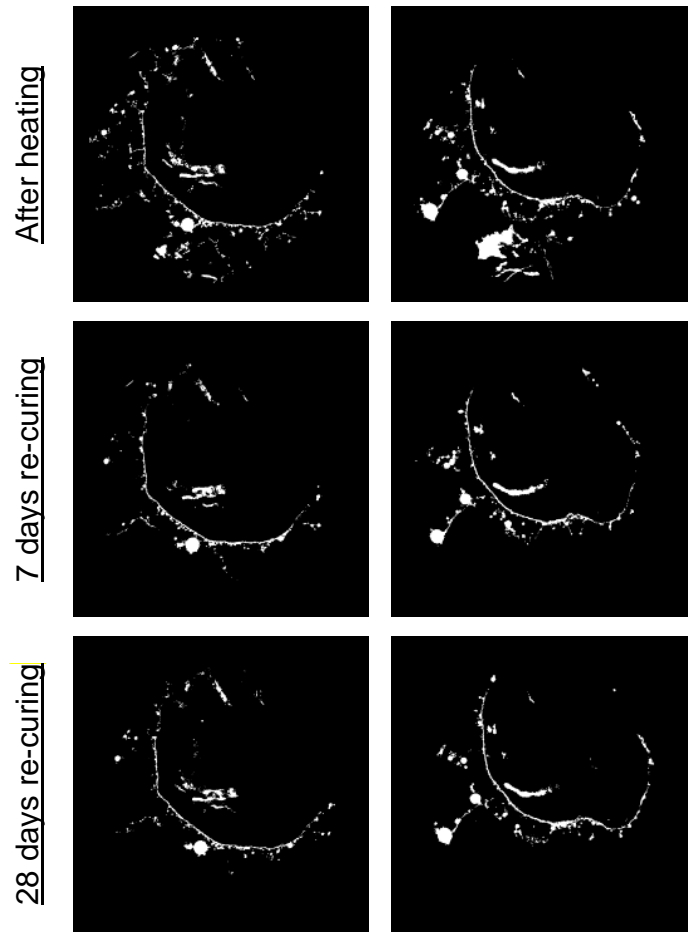

$\underline{\mathrm{h}=6 \mathrm{~mm}}$
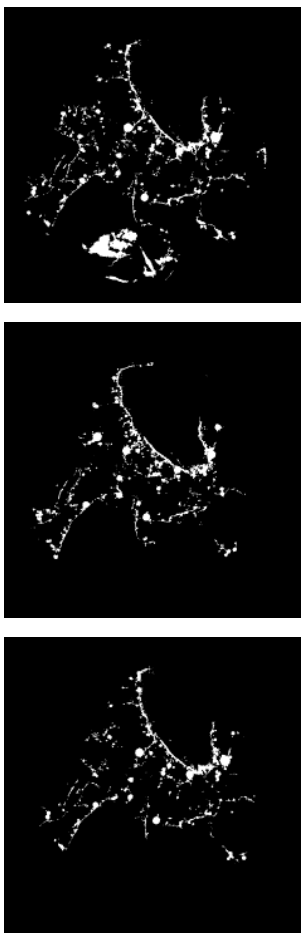

$\underline{\mathrm{h}=8 \mathrm{~mm}}$
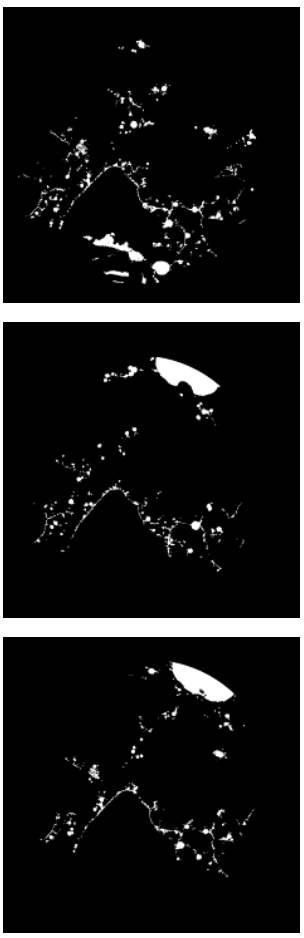

$\mathrm{h}=10 \mathrm{~mm}$
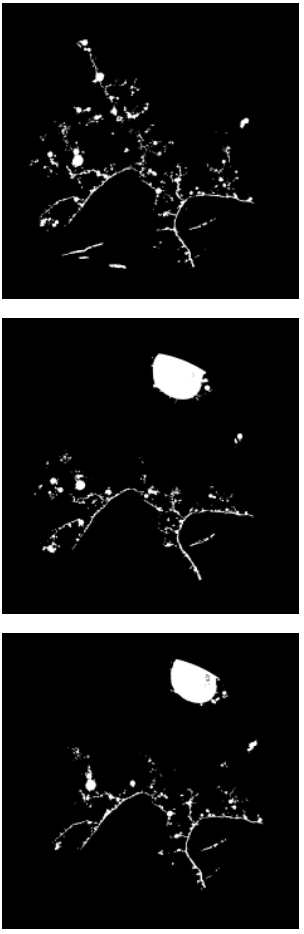

Figure 9: Images of connected pore space in air re-cured specimen 
$\underline{3 \mathrm{D} \text { visualization }}$
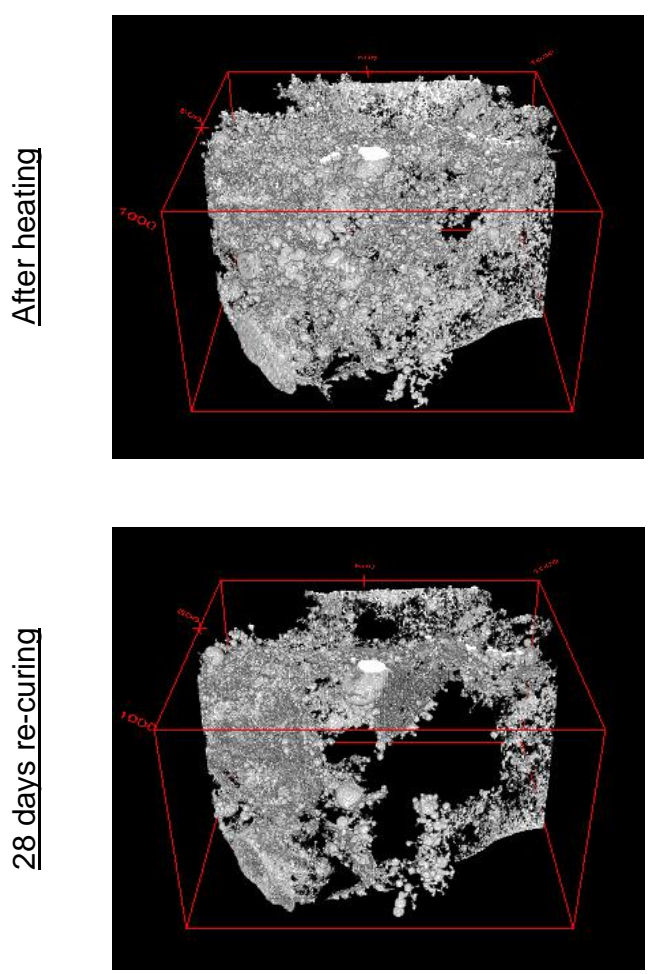

Pore size distribution
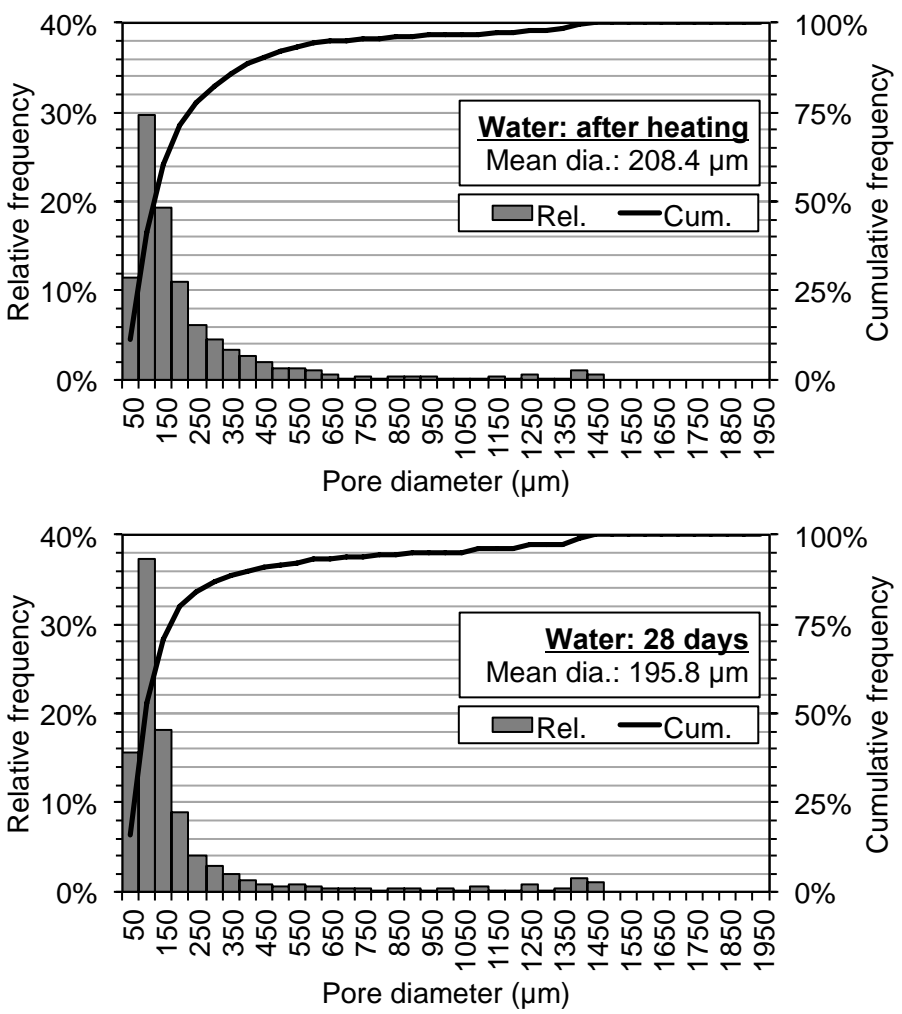

2

Figure 10: 3D visualizations and pore size distributions

of connected pore space in water re-cured specimen 
$\underline{3 D}$ visualization
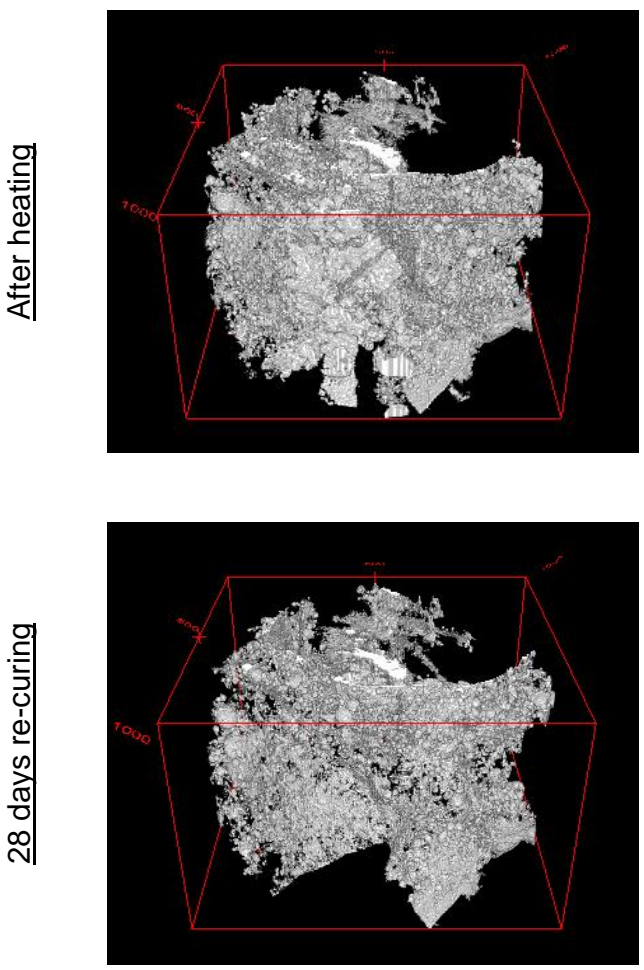

Pore size distribution
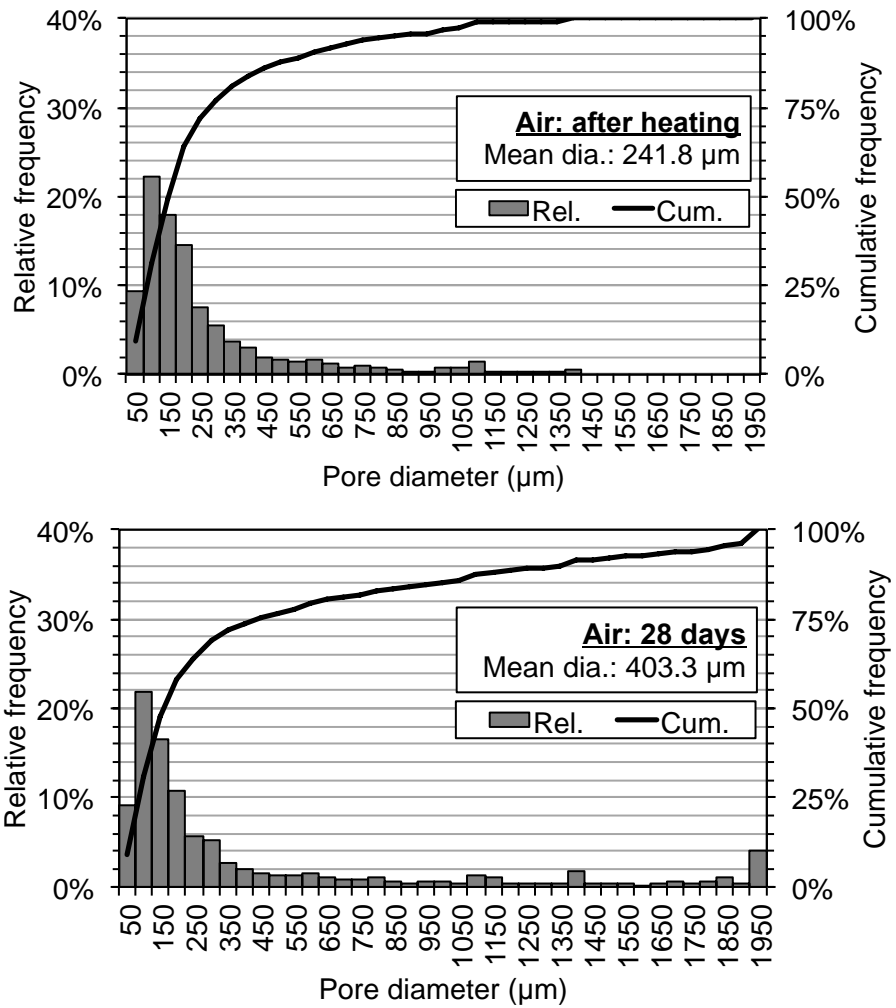

2

Figure 11: 3D visualizations and pore size distributions

of connected pore space in air re-cured specimen

5

6 